\title{
A SUSTENTABILIDADE AMBIENTAL: DA UTOPIA À EMERGÊNCIA
}

Tális Pereira Matias ${ }^{1}$

Ligia Tambasco Maesteghin²

Adriana Maria Imperador ${ }^{3}$

Resumo: Este artigo discute os principais tópicos ambientais relevantes ao contexto da pandemia pelo novo coronavírus. Por meio de pesquisas bibliográficas de trabalhos recentes e interdisciplinares, foi possível realizar uma abordagem sobre a relevância do saneamento básico no Brasil, assim como as relações entre a pandemia, poluição ambiental e biodiversidade, de forma que, perspectivas futuras puderam ser esboçadas a partir do conhecimento, recursos e conteúdo atual sobre sustentabilidade e qualidade de vida. O artigo também frisa a importância da propagação do conhecimento científico e da realização de projetos de Educação Ambiental visando o desenvolvimento do Brasil e bem-estar da população.

Palavras-chave: COVID-19; Sustentabilidade; Poluição; Educação Ambiental.

Abstract: This article discuss the main environmental topics relevants to the contexto of the new coronavirus pandemic. Through bibliographic reserchs os recente and interdisciplinar Works, it was possible to approch the relevance of basic sanitaions in Brazil, as well the relationships between the pandemic, environmental pollution and biodiversity, so that future perspectives could be outlined from knolewlegde, resources and current contente about sustainability na life quality. The article also talk about the importance of spreading scientific knowlegde and implament environmental education projects aimed at the development of Brazil and well-being of the population.

Keywords: COVID-19; Sustainability; Pollution; Environmental Education.

1 Universidade Federal de Alfenas. E-mail: talismatias12@gmail.com

Link para o Lattes: http://lattes.cnpq.br/2551120681904657

2 Universidade Federal de Alfenas. E-mail: ligiamasteghin@gmail.com

Link para o Lattes: http://lattes.cnpq.br/6450047927153337

3 Universidade Federal de Alfenas. E-mail: adriana.imperador@unifal-mg.edu.br.

Link para o Lattes: http://lattes.cnpq.br/6511962778909776 


\section{Introdução}

Segundo a OMS (Organização Mundial da Saúde), o objetivo do saneamento básico visa à saúde do homem, uma vez que sua ausência pode culminar em consequências na sua qualidade de vida. No Brasil o serviço de saneamento básico é negligenciado e sabe-se que as desigualdades em seu serviço estão presentes nas regiões do país, tornando-se uma ameaça à saúde pública já que a ausência de saneamento pode provocar a proliferação de doenças, sobrecarga no sistema de saúde, mortes e poluição dos recursos hídricos, apresentando-se como um caso de urgência com a declaração de pandemia no início de 2020.

As conexões entre meio ambiente, saúde, sociedade e economia nem sempre são claras, o que destaca a demanda por abordagens que discorram sobre essas questões, buscando a valorização e a importância do equilíbrio de tais elementos para a sustentabilidade e resiliência do país em momentos de crise como a pandemia pelo novo coronavírus.

Os problemas de saneamento básico no Brasil englobam questões fundamentais para o aprendizado e desenvolvimento de projetos públicos e privados eficazes para lidar com a demanda do aumento de higiene e demais cuidados com a saúde, além do alerta para a importância do monitoramento e coleta e tratamento de esgoto no país.

As variáveis associadas ao incremento e decremento de elementos poluidores também é alvo de relevância para ser observado no momento atual, assim como os efeitos e relações existentes entre biodiversidade, saúde e economia, pois afetam, ou podem afetar, direta ou indiretamente, o modo de vida ao qual a sociedade vem lidando.

Por meio de tais observações e considerações, é importante a discussão sobre as perspectivas futuras e planejamento ambiental, sobre uma visão holística, sustentável e inovadora, com a finalidade de buscar alternativas que potencializem os impactos positivos observados pela pandemia e mitiguem, minimizem ou revertam os impactos negativos derivados desta crise na medida do possível.

Desta forma, este trabalho apresenta-se como uma abordagem que visa a discussão de tais questões, considerando a diversidade de pesquisas científicas realizadas recentemente e as suas aplicações, contemplando alguns tópicos especiais em meio ambiente e sustentabilidade alinhados à pandemia pelo novo coronavírus e a importância da Educação Ambiental neste contexto.

\section{Metodologia}

O presente trabalho foi realizado por meio de um processo de revisão bibliográfica com a compilação e análise crítica de artigos, livros, notas e publicações técnico-científicas nas áreas multi e interdisciplinares que contemplam questões ambientais relevantes para a discussão sobre os efeitos 
e impactos ambientais da pandemia pelo novo coronavírus e perspectivas de futuro.

As buscas foram feitas em sites de pesquisa especializados como Scielo, Google Acadêmico, Springer Link e PubMed de trabalhos preferencialmente publicados nos 2 últimos anos. Para a busca foram consideradas as palavras chaves pandemia, meio ambiente, saneamento.

A estrutura metodológica começa com pesquisas sobre o panorama do saneamento básico no Brasil, buscando um resgate histórico e a compreensão das perspectivas do país nesta área com a chegada a pandemia. Em seguida passou-se para a investigação dos principais aspectos associados a poluição no contexto do coronavírus e dando continuidade abordou-se a ocorrência de impactos ambientais na biodiversidade.

Por fim, considerando os estudos e levantamentos realizados, foi feita uma abordagem sobre as perspectivas de futuro no contexto pós-pandemia, enfatizando algumas variáveis e possibilidade que podem ser úteis para a construção de um futuro promissor.

\section{Resultados e Discussão}

\section{Saneamento no Brasil e a Pandemia pelo novo coronavírus}

O saneamento é um fator fundamental para o desenvolvimento sustentável, assim como para a preservação e conservação da biodiversidade, saúde pública e qualidade de vida, sendo, portanto, um atributo de suma importância no planejamento urbano (BENINI et al., 2019, p.15).

As questões relacionadas a esse tema em uma abordagem recente do contexto de pandemia trouxeram avanços em pesquisas e novos elementos a serem considerados de forma global.

Um estudo realizado na Holanda, por exemplo, registrou a presença do novo coronavírus em 6 pontos diferentes de coleta de esgoto e os autores destacam que o monitoramento deve ser uma ferramenta sensível para monitorar a circulação do vírus (MEDEMA et al., 2020, p.6).

$\mathrm{Na}$ China, foi verificado que as fezes humanas podem formar altas concentrações de aerossóis virais, com propensão a causar surto na comunidade pela propagação por sistemas hidráulicos de esgoto, considerando que o vírus pode ser eliminado pelas fezes ou pela urina. Esta propagação viral também pode ocorrer pelo ar, gerando infecção em função da dispersão destes aerossóis fecais (MENG et al., 2020, p.2).

No mesmo estudo, os autores destacam medidas importantes para evitar essa propagação de aerossóis, como ventilação de última geração, sistemas de encanamento eficazes, verter meio litro de água em ralos semanalmente, manter a tampa do vazo coberta, rigor na higienização com desinfetantes e outras atitudes semelhantes. 
A Organização Mundial de Saúde (OMS) reforça a necessidade destas práticas de cuidado, e embora considere que o risco de transmissão da doença pelo esgoto seja mais baixa, ela ainda enfatiza, que como fragmentos virais foram encontrados em excrementos e devido a outros potenciais infecciosos e aos riscos de doenças provocadas por estes excrementos, as águas residuais devem ser tratadas, com sistemas bem projetados e bem gerenciados (OMS, 2020, p.3). Mas, como fazer isso em tão pouco tempo em países emergentes com condições de saneamento básico tão precárias? E mais, como seguir as orientações básicas de higiene, como lavar as mãos para comunidades que não dispõem de água em suas residências?

Uma realidade que enfrenta-se no Brasil no momento da pandemia da COVID-19 é a falta de acesso à água limpa e de qualidade para a higienização de grande parte da população, além da possibilidade de transmissão do coronavírus pela enorme carga viral despejada nos rios pelo esgoto que não é tratado (NASCIMENTO, 2020a, p.67).

No Brasil, são quase 35 milhões de pessoas sem acesso à água potável em quantidade e qualidade suficientes para preservar a saúde, apenas $53 \%$ dos brasileiros tem acesso a coleta de esgoto, portanto são quase 100 milhões de brasileiros que não têm acesso a este serviço. Da parcela que é coletada, apenas $46 \%$ é tratada, são apenas 21 municípios nas 100 maiores cidades do país que tratam mais de $80 \%$ do esgoto que é coletado, sendo as regiões mais pobres as mais afetadas (BRASIL, 2019a, p.73).

Esses dados parecem ser incoerentes devido a abundância hídrica do país, que retém $12 \%$ de água doce mundial (BENINI et al., 2019, p.21). Todavia, o problema está associado à localização geográfica e falta de políticas públicas eficazes para garantir este recurso que é direta ou indiretamente fundamental ao direito à vida, à saúde, à dignidade, à educação e ao trabalho (BENINI et al., 2019, p.33).

Outro problema que se vê no Brasil está associado aos poluentes emergentes. Dentre eles destaca-se aqui, em função do seu contexto da pandemia enfrentada no pais, a diversidade de reagentes que é oriunda de excessos de fármacos dispostos inadequadamente e excretados pelo organismo humano, que acabam integrando corpos d' água receptores e trazendo prejuízos ambientais, além de dificultadores para os sistemas de tratamento de efluentes que, na maioria dos casos, não dispõe de técnicas suficientes implantadas para tratar a abundância destes poluentes emergentes (BENINI et al., 2019, p.104; SOARES; SOUZA, 2017, p.127).

Uma das causas deste fenômeno é o aumento da automedicação, que pode ocorrer em função de marketing e outras formas de influências ao consumo de medicamentos de maneira descontrolada, trazendo riscos para a saúde pública e para o meio ambiente, o que exige esforços para orientação e conscientização sobre a real necessidade do uso de determinados medicamentos (SANTOS et al., 2020, p.55). 
Estes aspectos reforçam a função do estado de atuar regulando e indicando regras de conduta a fim de preservar a qualidade ambiental e assegurar a saúde pública, estando sempre alinhados e em coerência com aspectos científicos (SOARES; SOUZA, 2017, p.127).

Agregada a esta problemática, com o aumento de número de mortes no país e a abertura acelerada de novas covas, a preocupação com 0 gerenciamento destes processos se destaca.

O necrochorume tóxico derivado do processo de decomposição dos corpos e a presença de células contaminadas nos mortos podem se espalhar e sofrer interações cujos impactos ainda não são claramente previsíveis, o que destaca a importância do licenciamento ambiental destas novas atividades visando evitar contaminações generalizadas (NASCIMENTO; SENHORAS; FALCÃO, 2018, p.255).

Considerando o fato de que os cemitérios são fontes de contaminação de águas superficiais e subterrâneas, é importante que medidas técnicas de impermeabilização de covas sejam implementadas, pois existe o risco do novo coronavírus ser propagado a partir das interações físicas, químicas e biológicas que podem ocorrer nestes ambientes, uma vez que não se sabe ao certo quanto tempo 0 vírus permanece no corpo após 0 sepultamento (NASCIMENTO, 2020b, p.7).

Além disso, todos os objetos, acessórios e utensílios que tiveram contato com os infectados podem apresentar riscos de contaminação, como é o caso dos resíduos sólidos, especialmente os resíduos de serviços de saúde (BRASIL, 2010, p.3).

A Política Nacional dos Resíduos Sólidos (PNRS) frisa que estes materiais devem passar por processos de descontaminação, quando possível, para a destinação final (Brasil, 2010), sendo a incineração o método mais adequado. Entretanto, este é um processo caro e distante da maior parte do país.

No Brasil, 79 milhões de toneladas de resíduos foram gerados em 2018, sendo que $40,5 \%$ deste valor foram despejados em locais inapropriados. O país apresenta uma média de $380 \mathrm{~kg} / \mathrm{ano}$ de geração de resíduos sólidos urbanos por pessoa (ABRELPE, 2019, p.11). Se essa média for mantida, podemos estimar que cada pessoa contaminada pelo novo coronavírus pode gerar cerca de $380 \mathrm{~kg} / \mathrm{ano}$ de resíduos com potencial de propagação do coronavírus.

O Panorama dos Resíduos Sólidos no Brasil revela que:

Enquanto o mundo avança em direção a um modelo mais moderno e sustentável de gestão de resíduos, o Brasil continua apresentando as deficiências verificadas há vários anos, ficando abaixo dos indicadores médios de nações da mesma faixa de renda e desenvolvimento (ABRELPE, 2019, p.62). 
O mesmo relatório ainda destaca que:

(...) é latente a falta de recursos específicos para custear as operações do setor. Ao mesmo tempo, a tributação aplicada sobre todo o sistema é uma das mais elevadas e não favorece práticas sustentáveis (ABRELPE, 2019, p.62).

Estes déficits sanitários são promotores de doenças infectocontagiosas que trazem sérios problemas para a saúde pública no Brasil, são serviços públicos intimamente relacionados com o princípio da dignidade da pessoa humana, que deveriam receber fortes investimentos para minimizar efeitos graves como a propagação de doenças e desigualdade social (EDUARDO; NUNES, 2019, p.16).

Nestas condições, fica claro o desafio para conter a pandemia que se espalha rapidamente pelo país. Além das questões associadas ao acesso à água, coleta e tratamento de esgoto, existe também a preocupação com o enterro de corpos contaminados e gerenciamento dos resíduos sólidos contaminados ou potencialmente contaminados. Neste sentido, a pandemia no Brasil serviu para ressaltar a importância do investimento no saneamento básico no país.

\section{Poluição antes, durante e pós pandemia}

Foi a partir da revolução industrial que a atmosfera começou a receber cargas significativas de poluentes decorrentes de atividade humana. A poluição atmosférica representa uma das principais causas de doenças e mortes, em consequência dos altos índices de poluição que interferem diretamente nas pessoas com doenças cardíacas, como câncer de pulmão e doenças respiratórias, tornando-as mais susceptíveis (MARTIN, 2020, p.85).

De 2006 até 2016 houve um aumento de 14\% nas mortes em decorrência da poluição atmosférica no Brasil, com número de óbitos indo de 38.782 para 44.228 no mesmo período (BRASIL, 2019b, p.1). Estes números são preocupantes, entretanto, no contexto da pandemia, a redução dos poluentes atmosféricos tem sido um fato notável, o que demonstra ser uma das lições que devem ser aprendidas no período que se enfrenta no presente.

Com a pandemia do novo coronavírus e a consequente orientação de manter o isolamento social e diminuição da mobilidade, houve uma redução do fluxo de automóveis e atividades industriais influenciando diretamente as emissões de poluentes. Nesse período, segundo Instituto de Economia Agrícola IEA (2020) deixou-se de emitir um milhão de toneladas de $\mathrm{CO}_{2}$ diariamente no mundo, ocasionado pela queda no consumo de petróleo e carvão, notando-se principalmente nas grandes cidades uma melhora na qualidade do ar (MARTIN, 2020, p.86). 
As mudanças ocorridas no mercado do petróleo atingem diversos setores industriais, principalmente o de energia, podendo agravar emissões de poluentes posteriores. Com relação às usinas de carvão, maiores fontes poluidoras na geração de energia, nos meses anteriores a quarentena, notaram-se que as emissões de $\mathrm{CO}_{2}$ estavam em equilíbrio e a partir da pandemia a geração de carvão reduziu drasticamente com a redução das atividades (MARTIN, 2020, p.90).

Os satélites de monitoramento de poluição da Administração Nacional de Aeronáutica e Espaço (NASA) e da Agência Espacial Europeia (ESA) também verificaram reduções de poluição significativas em decorrência aos baixos níveis de dióxido de nitrogênio sobre a China e outros países (DINIZ, M.C et al., 2020, p.86).

Vários indicadores ambientais podem e são utilizados para o controle de poluentes no solo, na água e no ar, tanto no meio urbano quanto nos sistemas naturais, e por meio destes indicadores, diversos autores conseguem prever e planejar medidas de controle mais sustentáveis para lidar com a poluição residual, emergente e potencial (PIRES et al., 2017, p.7).

Desde o início da pandemia pelo novo coronavírus está havendo um aumento no consumo de produtos de limpeza e higiene, assim como produtos hospitalares, como máscaras, luvas e álcool, o que intensifica a geração de resíduos. A disposição inadequada destes materiais já vem poluindo corpos d' água e ambientes naturais e urbanos, o que é um impacto negativo. A Educação Ambiental pode contribuir, nesse sentido, por meio da mobilização social (BUSS, 2020, p.4).

Em contrapartida, a queda da geração de poluentes atmosféricos em função da redução da circulação de automóveis e estagnação de diversas atividades industriais, o que trouxe benefícios notáveis principalmente em grandes centros urbanos, parece contribuir para equilibrar esta balança.

Todavia, é importante reforçar que esta redução é momentânea, retomando as atividades que até então estão suspensas esta poluição tende a retornar ou até aumentar devido à demanda reprimida de circulação de pessoas e produtos. Portanto, um benefício derivado da pandemia que não deveria se perder tende a se perder, a menos que os modelos dominantes industriais e de transporte sejam revistos e modificados, visando a redução dos poluentes.

Neste sentido, fica notável a importância pela mudança nos padrões de consumo e nas atividades industriais, assim como fica evidente o desafio que pode ser abarcado pela Educação Ambiental para a sensibilização e redução da poluição e dos benefícios que esta redução acarreta, tratando de assuntos como redução de supérfluos, reutilização e reciclagem, incentivo ao consumo de produtos locais e menos processados, conciliando benefícios à saúde e meio ambiente. 


\section{Coronavírus e a biodiversidade}

A partir do surto do novo coronavírus e disseminação da pandemia, fezse necessário o distanciamento social, e como consequência as cidades vêm recebendo a presença de integrantes da fauna silvestre (DA-SILVA; COELHO, 2020, p.1).

$\mathrm{Na}$ Ásia, mais especificamente Tailândia, atribuiu-se a guerra por território e recursos por hordas de macacos. Esses macacos, da espécie Macaca fascicularis estavam acostumados a receber comida dos turistas que visitavam o local e com o isolamento social e proibições de viagens, esses locais tiveram uma queda no turismo por conta da pandemia, reduzindo também a oferta de alimento para os macacos. Dessa forma, a "invasão" dos animais se deu pela busca de recursos disponíveis nas cidades (DA-SILVA, COELHO, 2020, p.2).

A cidade de Nara, no Japão, recebeu também uma invasão de rebanhos de cervos, os quais eram encontrados em um parque, na busca por alimentos. Ou seja, estes animais são encontrados atualmente em locais onde não eram vistos, sempre em grande número (DA-SILVA; COELHO, 2020, p.2).

$\mathrm{Na}$ Itália, os canais que encontravam-se poluídos, com alguns dias de redução da atividade humana devido ao isolamento social para minimizar o surto da pandemia, passaram a ter um aspecto mais límpido, fazendo com que fosse possível a visualização de peixes, situação que anteriormente não era vista. Esse efeito foi reflexo da redução dos tráfegos de barcos (DA-SILVA; COELHO, 2020, p.4).

$\mathrm{Na}$ América do Sul, a cidade de Santiago recebeu a presença de uma onça-parda, provavelmente vinda de áreas montanhosas próximas. Tal aparecimento de animais em áreas urbanas tende a se tornar mais comum como resultado das reduções das distâncias que separam áreas naturais e ocupações humanas (DA-SILVA; COELHO, 2020, p.7).

Pesquisadores também ressaltam a importância da observação do desmatamento de florestas, como o caso da Amazônia e outras florestas tropicais, que podem ser um novo foco de zoonoses pela fuga de espécies do desmatamento e contato com seres humanos (ALLEN et al., 2017, p.1).

Existem evidências científicas que mostram que o SARS-CoV-2 não é um vírus propositalmente manipulado (ANDERSEN, et al., 2020, p.449). Dentre as possibilidades mais relevantes destacam-se processos de seleção natural e zoonoses que podem estar associadas a interferência antrópica em ecossistemas (DUARTE, 2020, p.3588).

No Brasil, esta realidade é preocupante, o desmatamento da amazônia aumentou 29,54\% no período de agosto de 2018 a julho de 2019, o valor estimado é de $9.762 \mathrm{~km}^{2}$ (BRASIL, 2019, p.1). Já de abril de 2019 até abril de 2020 o aumento foi de $171 \%$, que corresponde a $529 \mathrm{~km}^{2}$ de desmatamento na amazônia legal, em que $60 \%$ deste desmatamento ocorreu em áreas de 
privadas ou sobre estágio de posse, $22 \%$ em Unidades de Conservação (UC's), 15\% em assentamentos e 3\% em terras indígenas (BRASIL, 2020, p.1).

Estes resultados deixam claro a ineficiência das políticas de controle ambiental adotadas no período da ocorrência dos fatos, além de chamar a atenção para os riscos de zoonoses associadas à perda de biodiversidade na maior floresta tropical do mundo.

O desmatamento da floresta, assim como a falta de políticas públicas comprometidas com a preservação do ecossistema podem causar grandes impactos ambientais no surgimento e reemergência de várias doenças infecciosas, principalmente em países com alta biodiversidade e problemas ambientais, sociais e econômicos (NAVA et al., 2017, p.393).

$O$ investimento em pesquisas, assim como o desenvolvimentos de projetos emergenciais com foco na conservação da biodiversidade devem ser encorajados, visando a proteção contra doenças emergentes e os demais impactos provenientes do desmatamento. Ressalta-se também que os formuladores de políticas públicas devem dar importância ao reconhececimento de fatores antropogênicos, suas conexões ecológicas e a dinâmica de doenças, reservatórios e ambientes específicos para identificar regiões mais vulneráveis e implementar práticas de proteção, prevenção e Educação Ambiental (NAVA et al., 2017, p.398).

Estes estudos são promissores para a formulação de questionamentos sobre as pressões e influências sociais sobre os ecossistemas, e destacam a busca para o equilíbrio ambiental e a valorização moral e ecológica das espécies, sendo estes fatos, elementos promissores de discussão de Educadores Ambientais para a demonstração das relações entre sociedade e ecologia.

\section{Comunidades vulneráveis, meio ambiente e pandemia do novo coronavírus}

O sistema agroalimentar baseado em monoculturas e criação de animais contribui para a disseminação de pandemias em decorrência da destruição de ambientes florestais e proliferação de pragas e novos patógenos (ALENTEJANO, 2020, p.32).

As monoculturas ocupam $80 \%$ dos 1500 milhões de hectares disponíveis para a agricultura no mundo todo, possuindo como características a baixa diversidade ecológica e alta homogeneidade genética. Diante disso, há três características que favorecem a proliferação das principais epidemias das últimas décadas como a gripe aviária, a suína e o novo coronavírus: a primeira e principal é a criação industrial e extensiva de animais, somando-se ao contexto da agricultura em que $75 \%$ da terra de todo o planeta é usada para a criação de animais em massa, inclusive a criação de pasto e a terceira se dá a 
partir do crescimento descontrolado da mancha urbana e das indústrias (ALENTEJANO, 2020, p.33).

Com a interiorização da pandemia do novo coronavírus, acontecerá um aumento no montante da população indígena em alto risco, já que um terço dessa população reside em municípios considerados de alto risco para a pandemia, considerando fatores como exposição geográfica, socioeconômicos e demográficos relacionados à vulnerabilidade potencial a partir do COVID-19 na população residente em terras indígenas (ESCOBAR, 2020, p.138).

Em relação aos povos indígenas, a Fundação Nacional do Índio (FUNAI) recomenda que estes permaneçam nas aldeias, já que são considerados como povos susceptíveis à doença, uma vez que não tiveram o mesmo contato com vírus que povos não-indígenas tiveram. Outro fator que tornam as comunidades indígenas vulneráveis são aspectos ligados à falta de água potável e a desnutrição, aliado a isso, tem-se que a região amazônica que habita a maioria das comunidades possui número reduzido de hospitais com UTI's para casos mais graves (ESCOBAR, 2020, p.138).

Dentre outros grupos em situação de vulnerabilidade pode-se destacar os quilombolas, populações ribeirinhas, moradores de periferia e população de baixa renda e o motivo relaciona-se em condições socioambientais como desvantagens econômicas e sociais, falta de acesso à saúde, saneamento e informações de prevenção, falta de acesso à materiais de higiene e modo de vida coletivo que facilita a propagação do vírus (ESCOBAR, 2020, p.140).

Com a dificuldade de acesso muitas vezes estabelecida em comunidades vulneráveis, tem-se como alternativa ações de Educação Ambiental com o objetivo de compartilhar informações ao enfrentamento da pandemia da COVID-19. Como exemplo disso, pode-se citar a ocorrência de palestras e rodas de conversa em cooperativas de reciclagem na cidade de Poços de Caldas, Minas Gerais, realizados no primeiro semestre do ano de 2020 por docentes e discentes do Programa de Pós Graduação em Ciências Ambientais da Universidade Federal de Alfenas.

Durante essas conversas informais, foram discutidos conceitos básicos sobre o vírus, sua estrutura, a forma de transmissão da COVID-19, seus sintomas, o que fazer e onde recorrer caso tenha uma suspeita de contaminação e, principalmente, medidas de prevenção.

Vale ressaltar que, considerando que o vírus pode permanecer ativo por tempo limitado em materiais destinados à reciclagem e que estes são manipulados pelos catadores, esse grupo deve ser considerado vulnerável ao contágio. Além disso, as cooperativas nem sempre dispõe de equipamentos de proteção individual adequados às novas recomendações técnicas e, quando dispõe, novas adaptações são necessárias por parte dos trabalhadores. 


\section{Novas alternativas sustentáveis para o futuro}

No Brasil a pandemia vem acentuando as desigualdades sociais e econômicas do país, afetando a renda familiar, potencializando a miséria e demandando estratégias políticas de distribuição de rendas por parte do poder público (MOURA, 2020, p.3).

Uma alternativa que apresenta-se promissora para lidar com os impactos pela pandemia que se enfrenta hoje no mundo, é a substituição gradual e controlada dos sistemas econômicos lineares para sistemas circulares, que contemplam o desenvolvimento social, econômico e ambiental a partir da produção de tecnociclos no setor industrial, que são inspirados nos biociclos que ocorrem na natureza, um conceito conhecido como Economia Circular (EC) (KAAB et al., 2019, p.1018).

A Economia Circular pode ser adotada por uma grande amplitude de setores industriais, sendo promissora para a geração de emprego e renda de forma sustentável. Ela exige que as empresas modifiquem sua forma de pensar, implementando ações sustentáveis como reciclagem, reaproveitamento de água e materiais, redução de matérias primas, tratamento e otimização de efluentes, podendo apresentar diferentes tipos de design e fluxogramas (KAAB et al., 2019, p.1006; LÜDEKE-FREUND; GOLD; BOCKEN, 2019, p.56).

A agricultura também não pode ficar de fora deste contexto. Embora este setor possa não ser tão afetado pela a pandemia, considerar a importância da agricultura para a alimentação de cerca de 7,7 bilhões de pessoas em todo mundo, sendo 210 milhões no Brasil, (LUCENA; FILHO; BOMFIM, 2020, p.1) revela um horizonte de possibilidades para a inserção de modelos circulares nas cadeias produtivas, visando minimizar desperdícios e otimizar a produção.

Entretanto, para que ocorra essa mudança no modo de pensar e operar, deve haver sensibilização e conscientização, e para isso a Educação Ambiental dentro e fora das corporações, se fará necessária, pois é por meio dela que se constroem valores sociais, conhecimentos, habilidades, atitudes e competências para a conservação ambiental e sustentabilidade (PNEA, 1999, p.1), elementos fundamentais para o bom desempenho dos modelos de Economia Circular (LÜDEKE-FREUND; GOLD; BOCKEN, 2019, p.56).

Para que o sucesso destes novos desafios e oportunidades trazidos à tona pela pandemia ocorram, fica evidente que serão necessários investimentos nas múltiplas áreas do conhecimento, reconhecendo a interdependência do saber, as relações entre as diferentes formas de pensar, incluindo a importância do processo de Educação Ambiental como construção de conhecimento, valores sociais para conservação do meio ambiente e na promoção da qualidade de vida e sustentabilidade, além do favorecimento da formação de profissionais e lideranças preparados para o enfrentamento de um novo cenário ambiental, econômico e social mundial.

O momento atual mostrou e continua mostrando a importância da ciência e tecnologia, do investimento em equipamentos, laboratórios e recursos 
humanos, além destacar a importância no compartilhamento de informações científicas ao redor do mundo e disponibilização dessas informações em linguagem compreensível à população (CARVALHO; LIMA; COELI, 2020, p.2).

A promoção da cooperação internacional em pesquisa e no enfrentamento dos desafios da pandemia pelo novo coronavírus, visando emancipar países emergentes como o Brasil, permanece sendo um desafio para a Diplomacia da Saúde Global (MARTINS et al., 2017, p.237). Todavia, os resultados obtidos pela globalização das informações, se bem administrados, podem se tornar aliados para a superação deste desafio.

Tendo em vista a descentralização do conhecimento e a diplomacia global, práticas de Educação Ambiental devem ser estimuladas, e obstáculos como a falta de recursos, superados, uma vez que muitas atividades de Educação Ambiental fundamentais para a conservação, engajamento e participação social na busca pela solução de diversos problemas socioambientais, deixam de acontecer pela falta de recursos (PAULA; ALMEIDA; RUELA, 2020, p.94).

Além disso, a sustentabilidade deve ser incorporada ao contexto familiar e afetivo, para que ela promova a superação de fatores internos e externos que foram sedimentados durante séculos, moldados por paradigmas culturais e limitadores políticos vigentes, que afastam os indivíduos do sentimento de pertencimento ambiental, reconhecimento e valorização dos recursos naturais para a sua própria sobrevivência e qualidade de vida (FIALHO; CUNHA, 2018, p.331).

A partir de uma visão integrada dos trabalhos compartilhados nesta revisão, destaca-se a importância da modificação dos sistemas produtivos geradores impactos ambientais negativos de modo que eles possam ser incorporados a modelos mais sustentáveis, como a Economia Circular, e também que haja processos de Educação Ambiental e valorização da Ciência e Tecnologia, para que, em conjunto, essas ferramentas possam contribuir para a construção de uma sociedade mais humana e ecológica, reconhecendo a interdependência entre sociedade, meio ambiente e economia.

Ainda neste contexto, espera-se que a Educação Ambiental promova a sensibilização pela distribuição justa e igualitária dos recursos e dos benefícios de um ambiente saudável para todas as comunidades distribuídas no Brasil.

\section{Conclusões}

Por meio do levantamento bibliográfico presente neste artigo ficam claras as relações existentes entre meio ambiente, saúde e desenvolvimento sustentável. Percebe-se também a importância das ações do Estado para o enfrentamento da crise ambiental e suas associações com as questões ambientais, como a preservação da biodiversidade, acesso à água, coleta e tratamento de esgoto, além da valorização moral e ecológica da diversidade biológica dos ecossistemas e a sua importância na realização de diversos serviços ambientais. 
A relevância da Educação Ambiental como ferramenta transformadora de valores sociais no combate aos déficits socioambientais do país também é notável, frisando a importância de apoio e investimento em projetos de Educação Ambiental e sustentabilidade para cenário pós pandemia.

\section{Agradecimentos}

O presente trabalho foi realizado com apoio da Coordenação de Aperfeiçoamento de Pessoal de Nível Superior (CAPES) - Código de Financiamento 001. Também agradecemos ao Programa de Pós-graduação em Ciências Ambientais (PPGCA) da Universidade Federal de Alfenas (MG).

\section{Referências}

ABRELPE. Panorama Dos Resíduos Sólidos no Brasil. Panorama Dos No Brasil Sólidos Resíduos 2018/2019, p. 68, 2019. Disponível em <http://abrelpe.org.br/download-panorama-2018-2019/> Acesso: 04 Mai.2020.

ALENTEJANO, P.R.R. Reforma agrária, caos urbano, agronegócio e pandemia. Rev. Tamoios, ano 16, n.1, p. 32-38, 2020.

ALLEN, T. et al. Global hotspots and correlates of emerging zoonotic diseases. Nature Communications, v. 8, n. 1, p. 1-10, 2017.

ANDERSEN, K.G. et al. The proximal origin of SARS-CoV-2. Nat Med, v.26, n. 4 , p. $450-452,2020$.

BENINI, S.M.; DIAS, L.S.; AMÉRICO-PINHEIRO, J.H.P. Saneamento e Meio Ambiente. $2^{\circ}$ Ed. ANAP. 2019. Disponível em: $<$ https://www.amigosdanatureza.org.br/biblioteca/livros/item/cod/180> Acesso: 18 Mai.2020.

BRASIL. LEI No 12.305, DE 2 DE AGOSTO DE 2010., 2010. Disponível em < http://www2.mma.gov.br/port/conama/legiabre.cfm?codlegi=636> Acesso em 06 Mai.2020.

BRASIL. Diagnóstico dos Serviços de Água e Esgoto, 2019a. Disponível em $<$ http://www.snis.gov.br/diagnostico-anual-agua-e-esgotos/diagnostico-dosservicos-de-agua-e-esgotos-2018> Acesso em 05 Mai.2020.

BRASIL. Instituto Nacional de Pesquisas Espaciais (INPE), $2019 \mathrm{~b}$. Disponível em <http://www.inpe.br/noticias/noticia.php?Cod Noticia=5294> Acesso em 18 Mai.2020.

BRASIL. Ministério do Meio Ambiente, 2019b. Disponível em $<$ https://www.saude.gov.br/noticias/agencia-saude/45500-mortes-devido-apoluicao-aumentam-14-em-dez-anos-no-brasil> Acesso em 05 Mai.2020.

BRASIL. Sistema de Alerta de Desmatamento (SAD). 2020. Disponível em $<$ https://imazon.org.br/publicacoes/boletim-do-desmatamento-da-amazonialegal-abril-2020-sad/> Acesso em 18 Mai.2020. 
BUSS, P. M. De pandemias, desenvolvimento e multilateralismo Em, 2020. Disponível

$<$ https://www.arca.fiocruz.br/bitstream/icict/40774/2/De\%20pandemias\%2C\%20 desenvolvimento\%20e\%20multilateralismo.pdf> Acesso em 07 Mai.2020.

CARVALHO, M.S.; LIMA, L.D.; COELI, C.M. Ciência em tempos de pandemia. Cadernos de saúde pública, v. 36, n. 4, p. e00055520, 2020.

DA SILVA, E.R; COELHO, L.B.N. Sobre incursões da fauna silvestre em áreas urbanas durante a pandemia do novo coronavírus. Revista A Bruxa, v.4, n.2, p. 1-13, 2020.

DINIZ, M.C et al. Crise Global Coronavírus: monitoramento e impactos. Cadernos de Prospecção, v. 13, n.2, p. 359-377, 2020.

DUARTE, P. M. COVID-19: Origem do novo coronavírus. Brazilian Journal of Health Review, v. 3, n. 2, p. 3585-3590, 2020. .

EDUARDO, M.; NUNES, S. A regulação no setor de saneamento básico e o princípio da dignidade humana. RIMA, v. 1, n. 22, p. 1-20, 2019.

ESCOBAR, A.L. A interiorização da pandemia: potenciais impactos em populações em situação de vulnerabilidade na Amazônia. Revista NAU Social, v.11, n.20, p. 137-143, 2020.

FIALHO, R.G.M.; CUNHA, E.V. Sustentabilidade e afeto: a dimensão afetiva da sustentabilidade na família. Revista Brasileira de Educação Ambiental (RevBEA), v. 13, n. 4, p. 313-333, 2018.

$\mathrm{KAAB}, \mathrm{A}$. et al. Combined life cycle assessment and artificial intelligence for prediction of output energy and environmental impacts of sugarcane production. Science of the Total Environment, v. 664, p. 1005-1019, 2019.

LUCENA, C.C.; FILHO, Z.F.H.; BOMFIM, M.A.D. Atuais e potenciais impactos do coronavírus (Covid-19) na caprinocultura e ovinocultura. CIM, v.10, n.1, p.16, 2020.

LÜDEKE-FREUND, F.; GOLD, S.; BOCKEN, N.M.P. A Review and Typology of Circular Economy Business Model Patterns. Journal of Industrial Ecology, $v$. 23, n. 1, p. 36-61, 2019.

MARTINS, P. et al. Diplomacia da saúde global: Proposta de modelo conceitual. Saúde e Sociedade, v. 26, n. 1, p. 229-239, 2017.

MEDEMA, G. et al. Presence of SARS-Coronavirus-2 in sewage. medRxiv, 2020.

MENG, X. et al. Alert for SARS-CoV-2 infection caused by fecal aerosols in rural areas in China. Infection Control and Hospital Epidemiology, p. 1-4, $2020 . \quad$ Disponível em $<$ https://www.medrxiv.org/content/medrxiv/early/2020/03/30/2020.03.29.200458 80.full.pdf> Acesso: 03 Mai.2020.

MOURA, R.P. O Coronavírus e a denúncia das desigualdades contemporâneas a partir de um risco de alta-consequência . OSIRIS, n. 2009, p. 1-4, 2020. 
NASCIMENTO, D.M. Lavar as mãos contra o Coronavírus: mas, e a Água? Aps Em Revista, v. 2, n. 1, p. 66-69, 2020a.

NASCIMENTO, F.L. CEMITÉRIO X NOVO CORONAVÍRUS: IMPACTOS DA COVID-19 NA SAÚDE PÚBLICA E COLETIVA DOS MORTOS E DOS VIVOS. BOCA, v. 2, n. 4, p. 75-86, 2020 b.

NASCIMENTO, F.L.; SENHORAS, E.M.; FALCÃO, M.T. Necrópoles e os impactos ambientais: cemitério público municipal, Boa Vista-RR* ${ }^{\star}$. baru, v. 4, n. 2, p. 236-256, 2018.

NAVA, A. et al. The impact of global environmental changes on infectious disease emergence with a focus on risks for Brazil. ILAR Journal, v. 58, n. 3, p. 393-400, 2017.

OMS. Water, sanitation, hygiene and waste management for the COVID-19 virus. World Health Organisation, n. March, p. 1-9, 2020. Disponível em <https://apps.who.int/iris/bitstream/handle/10665/331846/WHO-2019-nCoVIPC_WASH-2020.3-eng.pdf> Acesso em 07 Mai.2020.

PAULA, E.L.; ALMEIDA, A.O.; RUELA, F.A. Ações de conscientização ambiental no município de Taiobeiras (MG): perspectivas e limitações. Revista Brasileira de Educação Ambiental (RevBEA), v. 15, n. 1, p. 83-96, 2020.

PIRES, S.M. et al. Indicadores de Desenvolvimento Sustentável: Instrumentos Estratégicos e Inovadores para Municípios Sustentáveis | 0 caso de Estarreja. [s.l: s.n.]. Disponível em < https://www.uc.pt/fduc/ij/publicacoes/pdfs/Livro_IDS_Estarreja_10_1_2017_seg .pdf> Acesso em 01 Mai.2020.

PNEA. LEI No 9.795, DE 27 DE ABRIL DE 1999: Dispõe sobre a educação ambiental, institui a Política Nacional de Educação Ambiental e dá outras providências. Diário Oficial, p. 2, 1999. Disponível em $<$ http://www.planalto.gov.br/ccivil 03/LEIS/L9795.htm> Acesso em 07 Mai.2020.

SAN MARTIN, M.C; SAN MARTIN, M.C. Condições atuais das emissões dos poluentes atmosféricos durante a quarentena da COVID-19 e as perpectivas futuras. BOCA, v. 2, n. 5, 2020.

SANTOS, M.C. et al. Perfil da automedicação por clientes de uma farmácia privada em cidade do Agreste de Pernambuco. Revista Brasileira de Educação e Saúde, v. 10, n. 2, p. 50-56, 2020. D

SOARES, A. F. S.; SOUZA, L. P. S. E. Contaminação das águas de abastecimento público por poluentes emergentes e o direito à saúde. Revista de Direito Sanitário, p. 33, 2017. 